\title{
Water intake meets the Water from inside the human body - physiological, cultural, and health perspectives - Synthetic and Systematic literature review
}

\author{
MUNTEANU Constantin ${ }^{1,2,3}$, TEOIBAS-SERBAN Droteea ${ }^{4}$, IORDACHE Liviu ${ }^{4}$, \\ BALAUREA Mariana ${ }^{4}$, BLENDEA Corneliu-Dan ${ }^{4,5}$
}

Editor: Mihail HOTETEU, Romanian Association of Balneology, hoteteu@yahoo.com

Reviewers: Gabriela Dogaru, Mariana Rotariu

Corresponding author: TEOIBAS-SERBAN Droteea, E-mail: doroteeateoibas@yahoo.com

1. Romanian Association of Balneology, Bucharest, Romania

2. Teaching Emergency Hospital "Bagdasar-Arseni”, Bucharest, Romania

3. Faculty of Medical Bioengineering, University of Medicine and Pharmacy "Grigore T. Popa", Iași, Romania

4. Clinical Emergency Regional Hospital Ilfov, Bucharest, Romania

5. "Titu Maiorescu" University, Faculty of Medicine, Bucharest, Romania

\section{Abstract}

Background. The average adult human body of 70 kilograms consists in about $67.85 \%$ water distributed evenly to an average of $70 \%$ in all major organs of the body: skin, muscles, brain, spinal cord, liver, heart, lungs, spleen, kidneys, pancreas and gastrointestinal tract. A smaller percentage is found in the bones $(30 \%)$, teeth $(5 \%)$ and fat tissue $(50 \%)$.

Objective. This review article attempts to present different perspectives on the physiological properties of water in the human body. We describe from the ancient Chinese medicine theory about water being one of the 5 elements of nature and its harmonious interrelation with the other elements in order to balance the human body, to the successful experiments of researchers which demonstrated waters' capability to change its molecular structure based on feelings, intentions and energy it was exposed to. We briefly describe the role of water for the human body and what effects can the lack of it have, especially dehydration with all the phases of severity. Also, we present the health benefits of drinking water and which type of water is best to consume. We shorty review the different types of natural mineral waters in Romania and the importance of the Romanian researches for balneology and how the waters cand be administrated in crenotherapy for different types of pathologies.

Methods. To elaborate our systematic review, we have searched for relevant open access articles and review articles in ISI Web of Science, published from January 2017 until August 2021. The terms used were water AND health in the title. Articles were excluded in the second phase if they did not reach the relevance citation criterion. The eligible articles were analyzed in detail regarding water importance for human health.

Results. Our search identified, first, $\mathbf{5 4 8}$ articles. After applying a PEDro like selection filter and, we selected $\mathbf{9 3}$ articles with a minimum of 8 points on our PEDro like filtering scale (good, very good, and excellent articles with a minimum of 5 citations per year). Detailed analysis of the 93 selected articles has conducted us to the elimination of 33 of them as being on a different subject than that of our article. To the $\mathbf{6 0}$ full articles retained for this systematic and synthetic article, we have added $\mathbf{1 0}$ articles found through a separate Google search, as being considered of high relevance for our subject and necessary to be included.

Conclusions. Water is essential for the entire planet and also indispensable for the survival of the human body.

Keywords: water intake, water balance, body water, water molecular structure, dehydration, crenotherapy

\section{INTRODUCTION}

The body of an average adult male is about $60 \%(\mathrm{w} / \mathrm{w})$ water, and the body of an average adult woman is about $55 \%(\mathrm{w} / \mathrm{w})$. There may be significant differences between individuals based on many factors such as age, health, weight, and gender. Body water is divided into intracellular and extracellular fluids. The intracellular fluid, which makes up about two-thirds of the body water, is the fluid contained in the cells. The extracellular fluid that makes up one-third of the body's fluids is the fluid contained in the areas outside the cells. The extracellular fluid itself is divided into plasma $(20 \%$ extracellular fluid), interstitial fluid (80\% extracellular fluid), and transcellular fluid, which is normally ignored in water calculations, including gastrointestinal, cerebrospinal, peritoneal, and ocular fluid (1).
The amount of water should one drinks is broadly discussed outside of scientific circles, but there is no onesize-fits-all answer. The daily four-to-six or eight-cup rule is for generally healthy people. This can also vary, especially if there is a water loss through sweat because of exercising or higher temperature. Drinking water is usually consumed as bottled water or as tap water. There are many mineral spring drinking waters on the market, which are much diversified in terms of mineral composition. Therefore, determination as to what extent the individual mineral nutrients determine the taste of the mineral water is essential, as such findings can help producers to provide ideal, health-improving nutrients for mineral water buyers (1). 
Freshwater comprises $3 \%$ of the total water on Earth. Only a small percentage $(0.01 \%)$ of this fresh water is available for human use. Groundwater and surface waters are the major sources of water around the world. Groundwater is a valuable natural resource and is believed to be comparatively much cleaner and free from pollution than surface water. As per global estimates, although groundwater comprises only $0.61 \%$ of the overall water resources of the world, $20 \%$ of the freshwater supply is characterized by it. Deterioration of groundwater can be due to geogenic and anthropogenic reasons (2).

Water connects the environment, culture, and biology, yet only recently has it emerged as a major focus for research in human biology. The research topics include: (a) markers of hydration (eg, urine specific gravity, doubly labeled water) important for measuring the impacts of water need on human biological functioning; (b) methods for measuring water quality (eg, digital colorimeter, membrane filtration) essential for understanding the health risks associated with exposure to microbiological, organic, metal, inorganic nonmental, and other contaminants; and (c) assessments of household water insecurity status that track aspects of unmet water needs (eg, inadequate water service, unaffordability, and experiences of water insecurity) that are directly relevant to human health and biology. Together, these methods can advance new research about the role of water in human biology and health, including the ways that insufficient, unsafe, or insecure water produces negative biological and health outcomes (3).

Water is essential for metabolism, substrate transport across membranes, cellular homeostasis, temperature regulation, and circulatory function (4). Systematic monitoring of the water quality parameters controlling hydrochemical processes is essential for sustainable usage of the water (5).

Water is a necessary component of life. Yet there is a clear recognition that current human use of available freshwater is not sustainable. The presence in drinking water of chemicals derived from human inputs into source water is of increasing public concern about both sustainability and public health. Ideally, the water one consumes should be free of harmful chemical and microbial contaminants. The Safe Drinking Water Act defines "contaminant" as any physical, chemical, biological or radiological substance or matter in water. However, source waters used to produce drinking water often contain both anthropogenic and naturally occurring contaminants. The anthropogenic contaminant load results from the complex interplay of increases in population growth, chemical, consumer product, and pharmaceutical usage per consumer, and the number of times a particular unit of water is re-used as it moves through the watershed. While it is technologically possible to remove most contaminants to levels below analytical detection limits, the implementation of the treatment technology required to do so could make the water prohibitively expensive. In addition, the presence of some minerals (e.g., magnesium sulfate, potassium chloride, sodium chloride, calcium chloride, magnesium chloride, and potassium bicarbonate) generally improves the taste of drinking water and their presence is considered beneficial (6). An estimated 748 million people worldwide lack access to safe drinking water sources, putting them at risk for waterborne illnesses (7). The water quality problems likely result from inadequate monitoring and maintenance of wells and septic systems in many communities (8). Human life, livelihood, health and wellbeing are closely linked with local ecosystems. Water is fundamental to all forms of ecosystem services including, provisioning, cultural, regulatory and maintenance; however contaminated water is also one of the major mediums of mortality and morbidity (9).

\section{METHOD}

To elaborate our systematic review, we have searched for relevant open access articles in ISI Web of Science, published from January 2017 until July 2021. The terms used were water and health in the title. Articles were excluded in the second phase if they did not reach the relevance citation criterion. The eligible articles were analyzed in detail regarding water importance for human health.

\section{RESULTS}

Our search identified, first, 548 articles. After applying a PEDro like selection filter and, we selected 93 articles with a minimum of 8 points on our PEDro like filtering scale (good, very good, and excellent articles with a minimum of 5 citations per year). Detailed analysis of the 93 selected articles has conducted us to the elimination of 33 of them as being on a different subject than that of our article. To the 60 full articles retained for this systematic and synthetic article, we have added 10 articles found through a separate Google search, as being considered of high relevance for our subject and necessary to be included as references.

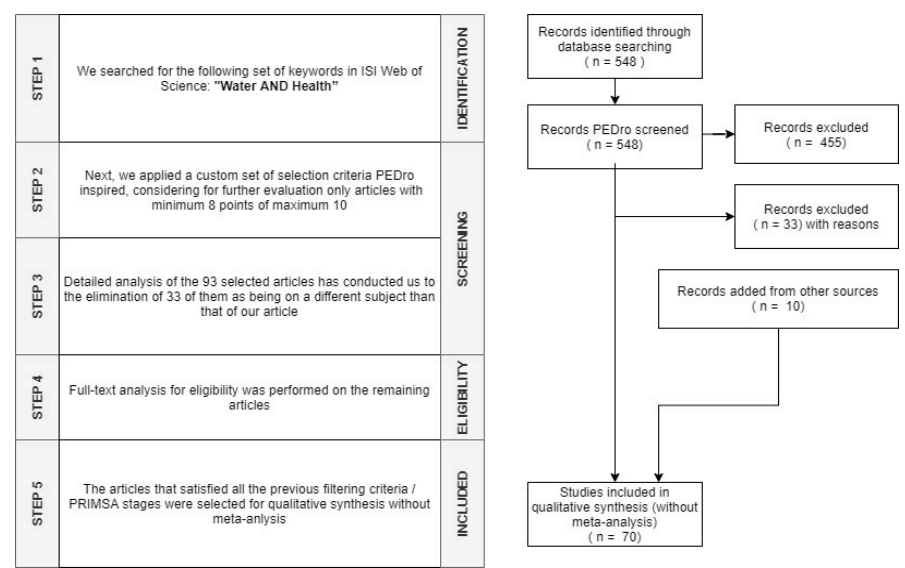

Fig. 1 PRISMA inspired flow diagram for articles search 


\section{WATER SYNTHETIC TOPICS}

Water physical-chemical properties and water quality There are different categories of waters intended for human consumption such as natural mineral waters and spring waters. Natural mineral waters may be distinguished from ordinary drinking water by their purity at source and their constant level of minerals. Spring waters are intended for human consumption in their natural state and are bottled at the source. The mineral nutrient contents are important characteristics of mineral water. Mineral nutrients are inorganic substances that must be ingested and absorbed in adequate amounts to satisfy a wide variety of essential metabolic and/or structural functions in the body. Mineral water contains a combination of the main cations $\left(\mathrm{Ca}^{2+}, \mathrm{Mg}^{2+}, \mathrm{Na}^{+}, \mathrm{K}+\right)$, anions $\left(\mathrm{HCO}^{-}, \mathrm{Cl}^{-}\right)$, and specific compounds (which can determine the medicinal value of water) in varying amounts. All mineral nutrient contents can be read from individual labels provided on the packaging.

Calcium plays numerous biological functions in the human body, of which one of the most important is skeleton mineralization. Calcium present in mineral drinking waters is a source of calcium intake. This, together with its excellent bioavailability, contributes to the maintenance of bone health. The 2009/54/EC directive classified natural mineral waters based on the mineral content, indicating "Water with Calcium" if calcium content is $>150 \mathrm{mg} / \mathrm{L}$ (10).

Because of the physical or chemical factors, much of the waters have a specific odor. The hardness of water mainly refers to the concentration of calcium and magnesium ions in water. The alkalinity of water depends on the contents of ions in water. When the alkalinity is higher, it will cause the decline of fragrance, precipitation, the difficulty of carbonation of $\mathrm{CO} 2$. The $\mathrm{pH}$ value will influence the discoloration of food, the precipitation, the deterioration of fragrance. The dissociation of chlorine will make the deterioration of color, the abnormal smell, the abnormal odor, and the deterioration of spice. The nitrate will produce an abnormal odor. The heavy metals ( $\mathrm{Fe}, \mathrm{Cu}, \mathrm{Mn}$, etc.) will cause the deterioration of color, the change of fragrance, the reversion of flavor, and the precipitation. The microorganism will cause corruption and the deterioration of taste (11).

\section{Water as the quintessential nutrient}

The human body consists of an average of 42 liters of water, the largest quantity (28 liters) being found in the intracellular fluid volume. This fluid consists of oxygen, nutrients, chemical messengers, and a small amount of proteins which enables all physiological processes to occur (2). The remaining 14 liters is represented by the extracellular fluid, consisting of blood plasma (3 liters), transcellular fluid (1 liter), and interstitial fluid, including the lymphatic system (10 liters) (3).
The WHO guideline value for drinking water salinity is $250 \mathrm{mg}$ of Chloride per liter $(\mathrm{mg} / \mathrm{l})$ for Chloride $(\mathrm{Cl})$ and $200 \mathrm{mg} / \mathrm{l}$ for Sodium (Na) and is based on taste threshold, not on health consideration (9). Drinking water sodium has serious implications for health, particularly for pregnant women. People exposed to slightly saline $(1000-2000 \mathrm{mg} / \mathrm{L})$ and moderately saline $(\geq 2000 \mathrm{mg} / \mathrm{L})$ concentrations of drinking water have a higher chance of being hypertensive than those who consume freshwater $(<1000 \mathrm{mg} / \mathrm{L})(12)$.

Bottled water

Bottled drinking water is a product that meets the drinking water requirements. No substances other than carbon dioxide may be added to packaged infant or spring water. This water can be obtained from any water source and treated the same way as to tap water, with the quality requirements being similar. In contrast to the above-mentioned types of bottled water, bottled drinking water can be artificially supplemented with minerals (calcium, magnesium, sodium, and potassium). If this happens, the list of supplemented substances in the water and the word sign "artificially supplemented with mineral nutrients - mineralized drinking water" should also be included on the label. Bottled drinking water can also be carbonated. Bottled drinking water is marketed under different names (besides trademarks it is, e.g., sparkling water or table water), but it must always be stated on the label that it is drinking water.

Water physiological role.

Water is a vital substance for the normal function of the human body, as a generator of hydro-electrolytic energy stored in ATP. Water has also properties of sustaining life such as promoting the function of proteins and enzymes by maintaining an optimal level of viscosity, maintains the youth of all body organs, and transportation of all vital elements throughout the body. There is also a direct link between water and the nervous system, for example, histamine is released only in relation to the thickness of the body fluids and thus it can promote the neural-transmission system, brain cells active substances are transported through so-called "water channels", nervous system cells contain $85 \%$ water and to complete the circle, the lack of water in the human body is also signaled by histamine.

It is widely known the importance of consuming an average of at least 2 liters of water every day to maintain a healthy body. This diminishes the risk of dehydration, improves skin density, reduces the risk of urolithiasis, urinary tract infections, hypertension, and coronary disease. The quantities of water intake recommendations vary from gender to age directly proportioned with the estimated energy consumed by the age/gender group: 2-3 years old children are recommended to drink $1300 \mathrm{ml}$ of water per day, young females from age 4 should drink $1700 \mathrm{ml}$ of water, the quantity raising as the child grows 
up -9 to 13 years old girl $-2100 \mathrm{ml}, 14$ to 18 years old young women $-2300 \mathrm{ml}$, and from 19 to $50+$ years old women should drink $2700 \mathrm{ml}$ of water per day. The male gender is recommended to drink a larger quantity of water per day because they have a larger estimated energy consummation: 4 to 8 years old boys should drink $1700 \mathrm{ml}$ water per day, 9 to 13 years old $-2400 \mathrm{ml}$ water per day, 14 to 18 years old young men $-3300 \mathrm{ml}$ and from 19 to $50+$ years old men the recommended quantity is $3700 \mathrm{ml}$ per day. Establishing the correct amount of water that should be drunk daily, we now address the quality of the water. In most countries tap water is a safe enough source for drinking in everyday life, however, in some industrialized large cities, there is a risk of contamination through the sewer system. The solution for this scenario was the controversial treatment of tap water with chlorine or fluorine. The chloride-treated water was controversial because it modified the taste of the water and the fact that it cannot protect from Cryptosporidium and Giardia intestinalis which contaminated throughout the years many cities from all over the world, became a problem. Fluorine-treated water was not as popular as the chloride one, but the controversy was even greater for this type of treatment of the water, which in many countries in which it was adopted, was rapidly discharged. Bottled water is known to be sterilized with ozone, which is known to destroy bacteria, and thus, can be a satisfactory alternant to tap water.

The ideal solution for hydrating is using a mineral curative water, highly recommended for its content of minerals and benefic substances, also known as crenotherapy.

The lack of water to the human body, dehydration, can lead to a series of disturbances and ailments in the human body. When the loss of water is higher than that of electrolytes - especially sodium - the extracellular fluid pressure surpasses the intracellular one, and compensatory mechanisms start to occur to equalize the two-fluid pressures, the result being the dehydration of the cell and the sensation of thirst. This is called hypertonic dehydration and can be caused by insufficient water intake and excessive water loss (13). When loss of water is surpassed by loss of sodium, the osmotic pressure decreases, and fluid enters the cell, resulting in extracellular dehydration and no sensation of thirst. This is called hypotonic dehydration and it can occur when the gastrointestinal fluids lost are replaced by water or by a solution that contains reduce quantities of electrolytes especially sodium. When loss of water and sodium is in the same quantities - isotonic dehydration - only extracellular fluid is reduced and can be caused by diarrhea especially in underdeveloped countries (13).

Water has numerous roles in the human body. It acts as a building material; as a solvent, reaction medium, and reactant; as a carrier for nutrients and waste products; in thermoregulation; and as a lubricant and shock absorber. The regulation of water balance is very precise, as a loss of $1 \%$ of body water is usually compensated within $24 \mathrm{~h}$. Both water intake and water losses are controlled to reach water balance. Minute changes in plasma osmolality are the main factors that trigger these homeostatic mechanisms. Healthy adults regulate water balance with precision, but young infants and elderly people are at greater risk of dehydration. Human water requirements are not based on a minimal intake because it might lead to a water deficit due to numerous factors that modify water needs (climate, physical activity, diet, and so on). On average, a sedentary adult should drink 1.51 of water per day, as water is the only liquid nutrient that is essential for body hydration (13). Fluids in the body are not pure water but solutions containing several solutes at precisely controlled concentrations. The main solutes in the extracellular fluid are salts (mostly sodium chloride, i.e. salt); bicarbonate $\left(\mathrm{HCO}_{3}\right)$, and small but important concentrations of calcium, potassium, and magnesium, as well as a wide range of substrates, such as metabolites and hormones. The intracellular fluid contains mostly potassium salts; small amounts of sodium, magnesium, and bicarbonate; a little chloride; and a very small quantity of calcium. Various physiological processes, such as eating or exercising, cause temporary disturbances in solute concentrations in the blood, however, sodium concentration is the most important osmolar control. The osmolality of the extracellular fluid is determined mainly by its concentration of sodium, and that of the intracellular fluid by the concentration of potassium. Sodium and potassium can cross cell membranes, and cells in the body are constantly pumping out sodium that has diffused into cells and pumping potassium back in as part of the regulation of cell function. Water can also cross cell membranes, but provided the osmolality of both intracellular and extracellular fluids are the same, there is no osmotic gradient that pushes water in or out of cells, keeping both intra- and extracellular fluid volume constant. The osmolality of body fluids is maintained at a constant level by adjusting water intake and excretion by controlling the amount of water lost as urine and the intake of water via the thirst mechanism. If plasma osmolality increases, then more water is needed, and signals are sent to the kidneys to conserve water, and thirst is stimulated. If plasma osmolality decreases, then water needs to be excreted, and the kidneys increase urine production. Body water volume is tightly controlled and, under normal conditions, fluctuates by less than $1 \%$ per day. Dehydration can affect consciousness and can induce speech incoherence, extremity weakness, hypotonia of ocular globes, orthostatic hypotension, and tachycardia. Dehydration can be defined as a $1 \%$ or greater loss of body mass (assuming that there is no weight loss 
occurring because of negative energy balance) due to fluid loss. Dehydration resulting in loss of body mass of $2 \%$ or more can result in impaired cognitive function, reduced physical performance, headaches, and symptoms of fatigue.

Under normal circumstances, the kidneys can excrete excess water, but extreme overconsumption of fluids can overwhelm this mechanism. In rare cases, this leads to hyponatremia (low levels of sodium in the blood), which causes lung congestion, brain swelling, headache, fatigue, lethargy, confusion, vomiting, seizures, and, eventually, coma. Overhydration is particularly associated with psychotic illness but has on rare occasions been reported in athletes and as a result of ill-advised 'detoxing' regimens, where large quantities.

The amount of urinary water loss is tightly controlled, as this is important not only for water balance but also for maintaining the correct solute concentrations in body fluids and for getting rid of waste products. Water is also lost by sweating when the loss of heat from the body by the process of heat radiation is not sufficient to dissipate excess body heat. Sweat also contains sodium and small amounts of other electrolytes, and so is a route of solute loss. The composition of sweat is highly variable, but it is inevitably hypotonic (more dilute) compared with plasma. The amount of sweat produced depends on many variables, including interindividual variation in sweat rates, environmental conditions, and levels of physical activity and fitness. Acclimatization to high temperatures allows higher, more sustained sweat rates and also increases the ability to retain sodium, causing a reduction in the sodium concentration of sweat Insensible water loss, which is the evaporation of water from the skin and lungs, may also be affected by factors such as environmental conditions and physical activity. Insensible water loss from feces depends on the amount of water in stools and is greatly increased in cases of diarrhea.

Thirst is the physiological mechanism that drives us to drink and is initiated when the brain detects a rise in plasma osmolality.

\section{Water in amniotic fluid (AF)}

When we develop in the womb, we are surrounded by amniotic fluid. During the development process of placenta and fetus vessels, water and solute from the maternal plasma pass to the fetus and the amniotic fluid. The amniotic fluid volume increases during the months of pregnancy up to $800 \mathrm{ml}$ in the 28th week and after that it slowly decreases to about $400 \mathrm{ml}$ in the $42 \mathrm{nd}$ week, because the skin of the fetus is now keratinized and the diffusion process between the amniotic fluid and the infant skin, placenta, and the umbilical cord, are lesser needed in the final stage of gestation (4). The relative stability of AF volume despite large fluid shifts suggests that control mechanisms exist. Vascular endothelial growth factor (VEGF) in the fetal membranes appears to be a mediator of this process. VEGF promotes blood vessel development within the amnion and influences the permeability of the microvessels, which perfuse the fetal and placental surfaces. The presence of aquaporin proteins in fetal membranes suggests the possibility of water channels as another potential regulator (14).

\section{Water needs for infants and children}

A newborn infant's body mass comprises $75 \%$ water the highest proportion of body water at any stage of a person's life. This decreases to approximately $60 \%$ by the time the infant reaches 6 months. Initially, an infant's diet is made up entirely of breast- or formula milk, which fulfills hydration and nutrient requirements. There are some physiological differences between infants and adults, including a greater surface area compared with body mass, higher water turnover, and less ability to sweat. This means that infants' fluid requirements are proportionally much greater than those of adults. As infants start to consume some solid foods, their fluid intake falls to about $120 \mathrm{ml} / \mathrm{kg} / \mathrm{day}$, and this will decrease further as more solid foods are included in the diet. As such, it is important to note that the recommendation of a fluid intake of $150 \mathrm{ml} / \mathrm{kg} /$ day is appropriate for young infants less than 6 months old who are exclusively breastor formula-fed. Like infants, children also have a higher proportion of body water than adults. They are also less heat tolerant and can become dehydrated when exercising, particularly in hot climates. Encouraging children to consume fluids regularly is particularly important in this context. Patterns of drinking behavior appear to be established in childhood, so young children must get used to drinking a range of appropriate beverages to maintain hydration. Dietitians generally recommend that children more than one year of age consume 6-8 drinks per day, with toddlers having relatively small drinks (e.g. $120-150 \mathrm{ml}$ per drink) and older children consuming larger drinks (e.g. $250-300 \mathrm{ml}$ per drink for a young teenager).

Water needs for adults

Adult women tend to have lower water requirements than men because of their lower body mass and lower proportion of body water. It is estimated that the total water needs of sedentary men are approximately $2.5 \mathrm{l} /$ day, increasing to $3.5 \mathrm{l} /$ day if moderately active and approaching $6 \mathrm{l} /$ day if active and living in a warm climate. There is less data on women's water requirements, but they are likely to be in the region of 0.5-1 1 lower than those for men. Women may need slightly more fluid when pregnant, and significantly more when lactating. The estimated additional requirement is approximately $0.3 \mathrm{l}$ /day for pregnancy, and between 0.7 and $1.1 \mathrm{l} /$ day for lactation. 
Water needs for older adults

Water requirements are not different for older compared with younger adults. However, several physiological changes take place during aging that may affect water balance in this population, putting older adults at greater risk of both overhydration and, more commonly, dehydration. The thirst response declines in older people, and total body water is also lower, because of loss of muscle mass and a proportional increase in body fat. There is a reduction in kidney function in old age, meaning the kidneys are less able to concentrate urine, increasing urinary water loss, and also less efficient at producing large quantities of urine to address overhydration. This may be exacerbated by medications that affect kidney function. Other medical conditions may also affect older adults' ability to drink, including dementia, frailty, infections, and difficulty in swallowing. Adequate fluid consumption is associated with many positive health outcomes in older people, including fewer falls, lower rates of constipation, and a reduced risk of bladder cancer in men. Conversely, dehydration in older adults increases the risk of many conditions, including urinary tract infections, confusion or delirium, renal failure and increased wound healing time, and dehydration is associated with increased mortality rates in hospitalized older adults.

Water characteristics and food complementarities

Water content of foods varies widely from over $90 \%$ in some fruits and vegetables to less than $5 \%$ in savoury snacks and confectionery. Dietary guidelines focus on the provision of nutrients rather than on the hydration requirements. Consuming foods that have a high water content may be particularly important for those looking to control or reduce their body mass as the water content of foods is inversely proportional to their energy density. Consuming plenty of water-rich foods may be beneficial both for hydration and for dietary quality. Some studies investigating rehydration after exercise have found that consuming water-rich foods as well as drinks may aid rehydration after an exercise-induced water loss, as this approach delivers both water and sodium.

In addition to providing water themselves, eating foods may also stimulate drinking. Studies have found that $75 \%$ of fluid intake occurs while eating, and fluid intake with food may facilitate chewing and swallowing, enhance palatability and reduce the effect of irritants such as chili. Although drinking water can supply all our hydration requirements, most people prefer to drink a variety of beverages. All beverages supply water, and some also provide nutrients that are beneficial for health. Beverages can also provide energy, and in the context of rising obesity levels, consumers need to be aware that drinks, as well as foods, contain energy. Although non-nutritive sweeteners have generally been considered metabolically inert, some data suggest that these sweeteners may have physiologic effects affecting hormone secretion, as well as intestinal absorption of glucose, that alter appetite and/or glucose metabolism (15).

Drinking water has the advantage of fulfilling hydration requirements without providing additional energy or adversely affecting dental health. Drinking water is provided by both tap water and bottled water, and, from a nutritional point of view, bottled and tap water are not significantly different. In both cases, mineral content varies according to the water source, and (depending on the source) drinking water may provide small amounts of calcium, sodium, and magnesium, although water is not a primary source of these minerals in the diet.

In the United States, it is estimated that about $22 \%$ of water comes from our food intake while it would be much higher in European countries, particularly a country like Greece with its higher intake of fruits and vegetables or South Korea (16).

The World Health Organization (WHO) assembled a diverse group of nutrition, medical, epidemiological, and other scientific experts and water technologists to address the possible role of drinking water containing calcium and/or magnesium as a contribution to the daily intake of those minerals. The overarching issue addressed was whether consumption of drinking water containing a relatively small contribution to total daily dietary intake of calcium and/or magnesium would provide positive health benefits, especially concerning the cardiovascular disease. Dietary reference intakes of $\mathrm{Mg} 2+$ are generally higher for males than for females but also depend on age. Drinking water sources may contain high levels of $\mathrm{Ca} 2+$, $\mathrm{Mg} 2+$, and $\mathrm{Na}+$ and may provide clinically important portions of the recommended dietary intake of these minerals. Physicians should encourage patients to check the mineral content of their drinking water, whether tap or bottled and choose water most appropriate for their needs. The water for food processing mainly includes the water for raw materials, the water for processing and the water for cleaning, etc. the water quality directly affects the food quality.

Water is the quintessential nutrient of life. Despite its well-established importance, however, it is ironically often ignored as a dietary constituent.

We can get water from almost all drinks and some foods in the diet. Food provides about $20 \%$ on average and this could vary widely depending on the types of food chosen. We also get water from all the drinks we consume, except stronger alcoholic drinks like wines and spirits. All these can contribute to dietary water, but also have other effects on health both positive and negative. The impurities in the water will cause a lot of impact on the food quality, mainly including the deterioration of food color, discoloration, coloration, abnormal odor, abnormal smell, turbidity, precipitation, crystallization, corruption, and some others. 
Water pollution and human health

One of the main routes of human exposure to pollutants is through drinking water. (17). There is widespread interest in dietary strategies that lower environmental impacts (18). Poor water quality has significant impacts on human health (19), and triggers the focus on the management of water quality and risk or prevalence of infectious disease (20). Measured water quality indicators include bacteria, disinfectants (residual free and total chlorine), disinfection by-products (trihalomethanes, bromate), aluminum, $\mathrm{pH}$, turbidity, and total organic carbon (21). Endocrine-disrupting chemicals have been detected also in drinking water from various countries (22). These chemicals exist as either natural or synthetic compounds and are capable of altering hormonal and homeostatic systems (23).

Consumption of drinking water and food containing high concentrations of nitrate and nitrite could cause diseases, such as cancer, methemoglobinemia, and enlargement of the thyroid gland, and diabetes mellitus. The positive effects of low concentrations of nitrates and nitrites include a cardioprotective effect (24). Most adverse health effects related to drinking water nitrate are likely due to a combination of high nitrate ingestion and factors that increase endogenous nitrosation (25). Health effects should be evaluated to prevent undesirable ones (26).

Freshwater bodies serve as the main water resources in rural areas used for drinking, cooking, and irrigation for agriculture in most communities that have little or no access to potable, safe water. They easily become polluted as a result of fast population growth, land development along river banks, and urbanization (27).

Nutrients and water found in domestic treated wastewater are reutilized in urban agriculture as a potential strategy to provide communities with access to fresh products (28). Surface waters are important sources of domestic water for humans, but they are more sensitive and vulnerable to contaminants (29). There is no systematic monitoring of groundwater quality in most countries, and there are large regions where little or no data are currently available (30).

Safe and sufficient water, sanitation, and hygiene prevent the spread of disease in healthcare facilities (31). Improvements in Water, Sanitation, and Hygiene are fundamental to promote child health in low and middleincome countries (32). Sixty percent of the overall diarrhea burden, $13 \%$ of the burden from acute respiratory infections, $16 \%$ of the burden of proteinenergy malnutrition, $43 \%$ of the schistosomiasis burden, $80 \%$ of the malaria burden, and $100 \%$ of both the burden from soil-transmitted helminth infections and trachoma burden are attributed to inadequate water use (33).

There are significant positive correlations between drinking water Uranium concentrations and incidence rates of tumors/growths and liver diseases (34).
Considering the high prevalence of, and risk factors associated with, indicator bacteria in drinking water stored in containers, which could increase the risk of contamination between source and point-of-use (35).

Watershed management can be defined as the integrated and iterative decision process that is applied to maintain the sustainability of resources through the balanced use and conservation of water quantity, land, vegetation, and other natural resources within the watershed (36). While in recent decades, many studies have explored the features and characteristics of urban blue and green spaces that are associated with positive health benefits, the healthy lifestyle promoting the role of artificial water canals has received little attention (37). Health-relevant microorganisms present in natural surface waters and engineered treatment systems that are exposed to sunlight can be inactivated by a complex set of interacting mechanisms (38).

The presence of biological pollutants, such as bacterial and viral pathogens, and emerging chemicals, such as endocrine disrupters, pesticides, and pharmaceutical and personal care products, are safety concerns in reclaimed water (39). Epidemiological studies have consistently observed an association between consumption of chlorinated drinking water with an increased risk of bladder cancer (40).

While fluoride $(\mathrm{F})$ is an essential anion to keep the human body healthy, high $\mathrm{F}$ intake could lead to serious health problems (41).

Exposure to lead through drinking water is a public health hazard, particularly for children. Lead is a neurotoxin and elevated blood lead levels in children have been associated with a range of adverse health effects, including learning disabilities, behavioral problems, and reduced cognitive function (42).

The Flint water crisis highlights the need for targeted risk communication strategies, improved environmental health infrastructure, enhanced surveillance, and primary prevention to identify and respond to the often invisible, disparate, and preventable environmental threats to the public's health. It has also created a unique opportunity for a diverse group of stakeholders to contribute to policy development (43).

Understanding the interactions between the involved human, animal, and environmental systems, and the processes within each of the systems is critical for efficient prevention and minimization of viral outbreaks. Water-related and other intervention approaches are implemented to mitigate the critical pathways and prevent the spread of viral disease. More deliberate efforts should be made to encourage environmental professionals to analyze the issues of viral disease through a One-Health lens (44). Concerns about the possible secondary transmission of the novel SARSCoV-2 via water are growing with evidence of its fecal 
elimination. Moreover, the results of in vitro experiments of prolonged virus survival with declining temperatures suggest that coronavirus excreted in feces could reach wastewater treatment plants in an infective state, especially in cool climates. (45).

The limited availability of quality water, both in rural and urban areas, is usually caused by anthropogenic factors more than natural processes. The anthropogenic factors which are eminent sources of water systems contamination span from domestic, agricultural, and industrial activities to poor waste management (46).

Water, sanitation, and hygiene (WASH) practices, in addition to safe water provision, a supply of adequate sanitation, and proper hygiene education can significantly reduce illness and death, improve child health outcomes, and socioeconomic development. According to 2015 WHO/UNICEF report, approximately $30 \%$ of the world's population did not have access to safely managed drinking water (located on-premises, available when needed, and free of contamination) and less than $40 \%$ of the world's population used a safely managed sanitation service (47).

Groundwater has been extensively developed and utilized as a source of drinking water due to its good quality. Our demand for clean and safe drinking water requires strategies to utilize groundwater effectively, safely, and economically. According to the WHO guideline, fluoride concentrations between 0.5 to $1.5 \mathrm{mg} / \mathrm{L}$ provide optimum benefits to human health. Exposure to high fluoride through drink water has been linked to endemic fluorosis. Fluoride enters the human body primarily through drinking water (48).

Water, sanitation, and hygiene (WASH) investments are widely seen as essential for improving health in early childhood (49).

According to biologists, all life forms came from the sea means water. We are living on this planet due to the blessing of water. From the dawn of civilization till now, humans (cave dwellers to city dwellers) have been using water for various seminal purposes: drinking, bathing, watering animals, and irrigating lands. However, this limited resource means a source of life under threat from the population, chiefly generated by human factors. Almost $71 \%$ of the earth's total surface is covered with water, only $2.5 \%$ of this amount can be considered as freshwater (50).

Water, sanitation, and hygiene interventions promoting household chlorination of drinking water, safe water storage, and handwashing with soap have the potential to reduce diarrheal disease incidence in children less than 5 years of age an estimated 30 to $75 \%$ (51).

Among the environmental factors, food and water contaminations are of particular relevance in the transmission of diseases. Several millions of children die each year from acute diarrheal diseases, and the majority of these deaths are likely due to contaminated food or water (52). The water-related exposome is a significant determinant of human health. The disease burden through water results from water-associated communicable and non-communicable diseases and is influenced by water pollution with chemicals, solid waste (mainly plastics), pathogens, insects, and other disease vectors (53).

Heavy metals and arsenic contamination in drinking water poses a serious threat to human life because of their toxicity, bio-accumulative nature, and persistence in the environment (54).

Chromium pollution of waters and groundwaters represents a serious environmental problem for EU countries. The genotoxicity of chromium, once it is introduced into human cells, can manifest favoring genomic instability, cancer onset, cell cycle arrest, and apoptosis (55).

The role of water in optimal feeding of breastmilk and non-breastmilk foods, however, has received minimal attention (56).

Analysis of heavy metal distribution in water is useful to trace the degree of water contamination induced by anthropogenic pressure (57). Lead $(\mathrm{Pb})$ in public drinking water supplies has garnered much attention since the outset of the Flint water crisis. $\mathrm{Pb}$ is a known hazard in multiple environmental matrices, exposure from which results in long-term deleterious health effects (58).

Lead, cadmium, arsenic, and mercury are very carcinogenic, while others are toxic. The potential health risk is associated with the accumulation of toxic heavy metals in tissues including Parkinson's disease, arsenicosis, acrodynia, selenosis, Alzheimer's disease, hair loss, mental imbalance, and abortion in women (59). Groundwater or aquifer vulnerability depends on the properties of the layers situated above the saturated zone to attenuate the pollutants' effects, by retention or neutralization by chemical reactions (60).

Quality and safe drinking water are essential for the sustainability of human health and the environment. Contamination of drinking water supplies poses a lot of threats to humans and the environment. Usually, the deterioration in water quality is due to organic and inorganic contaminations (61).

Water and food security are of global concern and key to achieving sustainable development goals. However, some contaminants are taken up by plants through different pathways, mostly still under research, and they accumulate in the food chain, compromising the safety of the food consumed by both humans and animals (62).

Trace elements produce double-edged effects on the lives of animals and particularly of humans. On one hand, these elements represent potentially toxic agents; on the other hand, they are essentially needed to support growth and development and confer protection against disease. The stochastic effects - for example, deriving from the 
excess or deficiency of certain elements - represent a highly underestimated criticality that could significantly affect the general costs of public health (63).

Aquatic environments are identified as an ideal setting for the acquisition and dissemination of antibiotic resistance, and human exposure to antibiotic-resistant bacteria (ARB) and antibiotic resistance genes (ARGs) in aquatic environments may pose an additional health risk (64).

The relation between the human body and water according to traditional Chinese medicine.

The five-element theory, which arose during the Chinese Warring States period (475-221 BC), is one of the outstanding representatives of this unique system. Through long-term development and living practices, the Chinese ancients recognized that wood, fire, earth, metal, and water are five indispensable, basic material elements of nature. Among these elements, there are relationships of mutual generation and mutual restriction. The normal transportation and transformation of the spleen's Qi can regulate the kidney's function of governing water to prevent water dampness flooding, i.e., earth restricts water. The moistening of the kidney's water can coordinate upward toward the heart to restrict the flaming upward of the heart fire, i.e., water restricts fire (65).

Similar to how Greek philosophers have discussed the origin of all things in the universe, ancient philosophers in China also debated on how the origin and consequence of all things can be explained and cycled. They postulated that the universe is composed of five fundamental elements, and then they developed the theory of how the universe was created and undergoes a cycling process. The 'five elements theory' not only defines the character of each element but also emphasizes the mutual interaction and rotation of the elements under an interactive system. The five elements, or five phases, are orderly classified by five materials as follows: wood, fire, earth, metal, and water. Each element has its own literal and philosophical meaning. The wood type is represented by a tree that grows straight and is abundantly spreading out. The fire-type is represented by a state of combustion that generates heat. The earth-type will likely establish a foothold to newly change an outdated system. The metal type is represented by the formation of a hard crystal. Lastly, the water-type is represented by a stream that seems to run out of a solid melting. The attributions of each element in itself do not reveal their identities, but rather, reveal their color when under reciprocal interaction. There are two flows among the five elements, i.e., the mutual nourishment cycle and mutual restrain cycle, which has organically positive or negative influences on each other. Water, excreted from the kidney is reminiscent of the flow of a river; therefore, the kidney has a water-type attribute (66).
Modern medicine agrees that the liver can sustain the heart (both of them being Zang-organs in ancient Chinese medicine), thus it can be said that wood can sustain fire. Similarly, it can be said that the kidney can sustain the liver (both of them being also Zang-organs), and thus water can sustain the wood (the growth of it). The organs which are directly linked to water besides their representative element are the lung - which if it dominates the qi instead of the yin can manage the water and skin diffusion, promoting sweat (which is a vital process of the body's thermoregulation), the spleen which as a qi source, can manage many of the blood and body fluids' circuit through the major organs of the body and the kidney - which stores essence transforming the qi, thus producing blood, modifying and maintaining the necessary nutrient from the body fluids, sustaining the health of the body.

The theory of molecular water changes based on environment excitants or inhibitors.

Some believe that water is a "blueprint for our reality" and that emotional "energies" and "vibrations" could change the physical structure of water. The water crystallization experiments of Masaru Emoto consisted of exposing water in glasses to different words, pictures, or music, and then freezing and examining the aesthetic properties of the resulting crystals with microscopic photography. Masaru Emoto claimed that water exposed to positive speech and thoughts would result in visually "pleasing" crystals being formed when that water was frozen, and that negative intention would yield "ugly" crystal formations. The criticism of the experiments of Masaru Emoto mostly reflects the prevailing materialistic dogmas, which do not allow these effects. Emoto shares the fate of experimenters studying water memory and homeopathy. "Homeopathy" is indeed a word making skeptics growl and drool: one can hardly imagine a more impressive demonstration of words on the water than this! An almost- Nobelist Benveniste was labeled as a swindler as he announced experiments providing support for water memory and homeopathy (67).

The experiments with the water or plants held under the pyramid came from the ancient Egyptian legends which claim that the geometric shape influences matter, that if perishable plants were placed inside the pyramid, their life duration will be prolonged. This theory explains that the shape of the pyramid can capture external energy which preserves for a long time any type of matter placed inside of it, delaying decomposition by the means of inhibiting the growth of microorganisms which promote decay. These experiments suggest that there is a link between the molecular structure of water and emotions, intentions and energy that are sent to them. Also, we can assume that if the plants used in the experiments responded well to positively treated water, then such will respond to the human body. 
Treatment through water

Hydrotherapy is a field that pursues disease treatment or health effects using various properties of water for therapeutic purposes and is used synonymously with water therapy, aquatic therapy, pool therapy, and balneotherapy. Hydrotherapy is a therapeutic modality that maximizes the characteristics and advantages of water and is considered in clinical and alternative medicine to have an excellent therapeutic effect, with few adverse effects. Water offers various advantages, including being abundant; not physiologically irritating; and having excellent solvency, excellent viscosity, high heat capacity, and high heat conductivity (68).

Although hydrotherapy has a worldwide appreciation for its beneficial properties in diminishing pain, reducing inflammation, and edema, cures skin infections and vast more other ailments at different levels of the body, especially the muscle and joint affections.

The Romanian scholar researchers made many clinical studies and established which type of water is beneficial for every specific pathology which can be treated by this method. All types of studied waters came naturally from springs and their elements develop through a natural process, without human intervention whatsoever. Thus oligo-mineral waters, depending on their temperature, can drink the hotter ones (acrato-thermal water) for digestive and renal-vesical conditions because this water has antalgic and antispastic properties and the colder ones specially for renal lithiasis. Alkaline waters, which contain a minimum of 1 gram of sodium and potassium bicarbonate per liter of drinkable water, can be drunk as therapy for digestive ailments, and its effect may differ depending on the moment of ingesting the water reporting to the meals: if ingested 1 hour and $1 / 2$ before the meal it inhibits gastric secretion if ingested during the meal it stimulates the gastric secretion and if ingested after the meal it has a double effect - initial inhibition of the gastric secretion, followed by stimulation through sodium chloride and carbon dioxide which interacts with the chlorohydric acid in the digestive tract. Alkaline waters also fluidify and eliminate mucus secretion from the stomach, reduces inflammation in the urinary tract mucosae, accelerates the evacuation of the gastric content, and alkalinize the urine $\mathrm{pH}$. Chlorate sodium waters are waters that contain sodium chloride over 1 gram per liter and its use in crenotherapy is mostly for the digestive system condition, where the purpose is to increase secretion and motility. Carbonaceous waters are mineral waters that contain a minimum of 1 gram of dissolved $\mathrm{CO} 2$ in 1 liter of water and also because it is naturally produced, it may contain chlorate sodium, iron, or sulfur in its componence. Carbonaceous waters are used in crenotherapy for their properties to stimulate saliva and gastric secretion, activate gastric motility, stimulate gastric acidity, stimulates pancreatic and biliary secretion, and influence urinary $\mathrm{pH}$. Sulfurous waters are mineral waters that contain a minimum of 1 gram of sulfur (in form of $\mathrm{H} 2 \mathrm{~S}$, HS, or sulfurous colloidal complex) and because of the instability of the compound, once the sulfurous water comes in contact with air and changes its color and smell, it is recommended that this type of water should be drunk directly at the stream without transporting it. Sulfurous mineral waters can increase gastric secretion, stimulate intestinal peristalsis, has a cholagogic effect, and decrease blood glucose.

These are just a few examples of the vastly spread natural mineral waters from Romania and only some of the natural properties which can be used for treatment through crenotherapy.

Sulfurous mineral waters have been traditionally used in medical hydrology as a treatment for skin, respiratory, and musculoskeletal disorders. However, driven by recent intense research efforts, topical treatments are starting to show benefits for pulmonary hypertension, arterial hypertension, atherosclerosis, ischemiareperfusion injury, heart failure, peptic ulcer, and acute and chronic inflammatory diseases (69).

Aquaporin-4 (AQP4) is a water channel expressed on astrocytic endfeet in the brain. The role of AQP4 has been studied in health and a range of pathological conditions. Interest in AQP4 has increased since it was discovered to be the target antigen in the inflammatory autoimmune disease neuromyelitis optic spectrum disorder (NMOSD). Emerging data suggest that AQP4 may also be implicated in the lymphatic system and may be involved in the clearance of beta-amyloid in Alzheimer's disease (AD) (70).

Main types and sources of mineral therapeutic waters:

Chlorosodic or salty water. Very numerous, and used in internal cure: if they have the concentration to $15 \mathrm{~g}$ per liter in digestive diseases (gastric hypoacid, etc), in chronic bronchitis, chronic rhinitis; for the external cure when the concentration exceeds $15 \mathrm{~g}$ per thousand (can reach up to $250 \mathrm{~g}$ ), are indicated in rheumatic diseases. Stations where there are: Sovata, Amara, Ocna Sibiului, Techirghiol, Slãnic Prahova, Govora, Bazna and Olaneşti (and iodine) etc.

Sulfate waters ( $1 \mathrm{~g}$ per thousand sulfates). They are sodium sulfate or glauberiene water, magnesium or bitter, calcium or gypsum, and vitriol (with $\mathrm{Fe}$ and $\mathrm{Al}$ ); and used only for internal cure in digestive disease (intestinal, hepato-biliary). Are drunk in the morning an empty stomach in chronic constipation, colecistatonia, obesity, etc. can be found at Slãnic, Bãlţãteşti, etc.

Ferruginous waters (10 g iron per thousand). Are always carbonated, but can be salty, alkaline, calcium, etc. iron has an important role in the body. Ferruginous waters are used for internal cure, only from the spring, during the meals, otherwise, the iron in contact with air becomes inactive. Only bivalent iron is active, being 
absorbed in the presence of $\mathrm{HCl}$ and $\mathrm{C}$ vitamins. Ferruginous waters are indicated for iron deficiency anemia, gastric achylia, operated stomach, etc can be found at Vatra Dornei, Tuşnad, Buziaş, Covasna, etc.

Iodine water (1 mg iodine per thousand). Iodine, whose metabolism is controlled by the thyroid gland has been used for a long time to treat chronic rheumatism, aterosclerosis, hypertension, etc. these waters are used for internal and external cures. reumatismului cronic, aterosclerozei, hipertensiunii arteriale etc. The resort is situated near the salt mines: Govora, Olanesti (iodine, salty, and sulfate waters), Bazna (salty and iodine), etc.

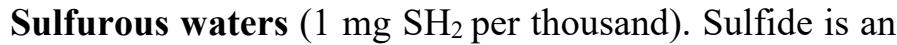
element with many roles for the body. He enters in the amino acids composition, indispensable to the body (cysteine, arginine, etc. hence the importance of sulfur water in chronic mucosal lesions (bronchitis, rhinitis). Sulfur is a part of the connective tissue constitution. Because rheumatic is considered a collagen disease, sulfurous waters are the major indications. Sulfur participates in insulin constitution and hence the indication of sulfurous water in diabetes. Finally, sulfur has a desensitizer and antiallergic role, with indications in asthma and some dermatoses.

Oligometalic waters ( $1 \mathrm{~g}$ per thousand) are poorly mineralized and can be hot or cold. They contain Na, I, S, Ra (Geoagiu, Felix, with 40-45 degrees temperature) and are used in musculoskeletal disease. The cold waters are used for internal cure (bottled for commercial use). For example Olãneşti, Cãlimaneşti, used in digestive and urinary diseases.

Carbonated waters ( $1 \mathrm{~g} \mathrm{CO}_{2}$ per thousand $)$ are indicated for internal (digestive, chronic, with hyposecretion diseases) and external cures (cardiovascular diseases, hypertension, arthritis, Raynaud's disease, acrocyanosis, posflebitic sequels, venous insufficiency).

Alkaline waters (1 g bicarbonate per thousand) don't exist in pure form in our country, are meet as combinations (tero-alkaline waters with $\mathrm{Mg}, \mathrm{Ca}$ ), alkaline, sodium-chlorine, carbonated, sulfurous, sulfate, ferruginous waters. They are used in the internal cure, especially for digestive and hepato-biliary diseases. The external cures are used for inhalations and spays (in respiratory diseases). The alkaline waters can be found at Sângeorz, Hebe, Slãnic Moldova, Malnaş, Bodoc. In Karlovy-Vary (Czech Republic) can found alkaline sulfurous waters.

Tero and tero-alkaline waters ( $1 \mathrm{~g}$ per thousand) contain bicarbonate linked to $\mathrm{Ca}$ or $\mathrm{Mg}$ and have as main indications digestive diseases (gastritis, colitis, ulcer, chronic enterocolitis, rachitis, allergies, etc.). Such waters are found at Borsec, Covasna. At Sângeorz, Slãnic. $\mathrm{Ca}^{2+}$ is the main element of these waters.
AQUA / Water SOMMELIER - education to see the water through a new paradigm

Generally, as tap water flavor is among the major concerns for water supporters, only a minor percentage is used for drinking, increasing the importance of bottled water composition and flavor. It needs to be kept in mind that consumers assess their tap water primarily by its initial assessment via taste, odor, as well as appearance. However, similar preferences and assessments can be also seen in quality of drinking water produced by for example reverse osmosis or other filtration methods, as well as, for example, when optimizing drinking water taste by appropriate adjusting of mineralization (measured by TDS). In any case, it is important not to forget also about the role of consumer preferences, which are also valid in cases of the mineralization of water, wherein the preference ratings vary. However, it is necessary to uncover taste determinants as it is the initial basis for water industry providers in understanding perceptions and preferences among types of drinking water.

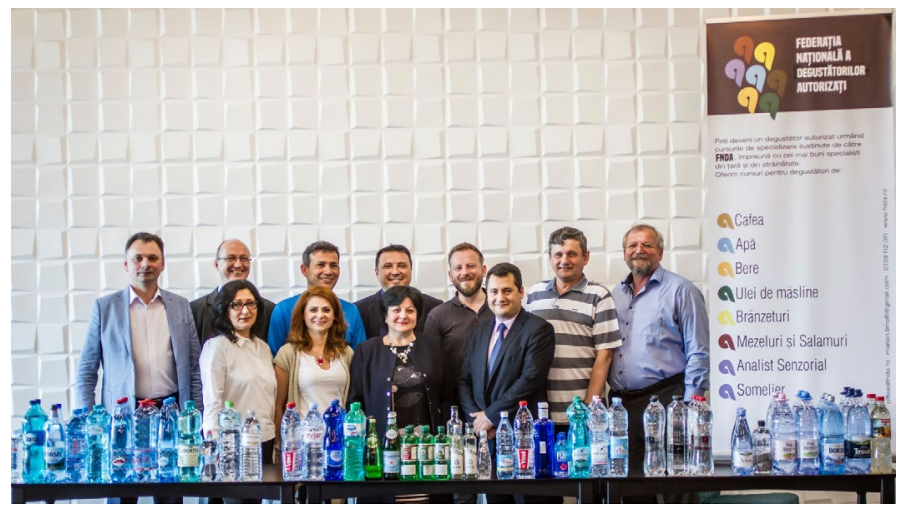

Fig. 2 Romanian First Team of Water/Aqua Sommeliers The role of hydration in the maintenance of health is increasingly recognized. Hydration requirements vary for each person, depending on physical activity, environmental conditions, dietary patterns, alcohol intake, health problems and age.

The water used for drinking is provided through regular public water supply and the official sanitary controls ensure their quality and hygiene, granting a range of variation for most of its physical and chemical characteristics, being sometimes these differences, though apparently small, responsible for some disorders in sensitive individuals. Hence the advantages of using bottled water, either natural mineral water or spring water, which are required by law to specify their composition, their major components and other specific parameters. It is essential to take this into account to understand the diversity of indications and favourable effects on health that certain waters can offer.

Anyone can improve their sensory skills. This is done primarily through conscious tastings of various mineral water brands or reference substances. When tasting, one should practice analysing and describing the smell and 
taste repeatedly. It is only through direct experience that sensory skills are properly trained, and professional tasters have acquired their expertise only through continuous practice and training seminars. The training programmes cover the following topics:

» water diversity

» definitions and legal terms

» mineral composition and nutritional physiology

») marketing and sales

» mineral water testing

» mineral and curative water sensory assessments

» water and wine

») excursions to mineral source operations

In order for the consumer to be able to find out about the sensory diversity of mineral water and health-related properties of curative water, experts are needed to taste, enlighten, explain and advise on the compelling aspects of this valuable beverages. Water Sommeliers or Aqua Sommeliers are well-trained, competent advisors that add value to natural mineral waters and natural curative waters. In restaurants, a Water/Aqua Sommelier is a valuable asset who can enlighten guests about the advantages and variety of mineral waters as a suitable accompaniment for certain dishes, with wines and coffee. $\mathrm{He} / \mathrm{she}$ is also responsible for presentating this quality beverage at the table. In addition, the Water Sommelier is the restaurant's agent, responsible for the selection and purchase of mineral waters as well as the creation of a mineral water menu. Organising mineral water or water/wine tastings for interested guests is also an essential task of the Water / Aqua Sommelier in restaurants and hotels.

\section{Conclusion}

Water is essential for the entire planet and also indispensable for the survival of the human body. It can destroy solid rock and plants if it overfloods, but it can also nurture and grow all living things on the planet. It has memory and magnetic properties. It can drown a human being, or it can save him from various diseases through its wonderful healing effects. It comes from the depth of the earth, evaporates, rases to the sky and then comes back down again to ensure life on this planet. Drink water! Water is life!

\section{Funding}

This research did not receive any specific grant from funding public, commercial, or not-for-profit agencies.

\section{Author contribution}

All authors have consistently contributed to this article.

\section{Declaration of interests}

This article does not contain any studies with human or animal subjects. This study did not require written consent from patients. The authors declare that they have no known competing financial interests or personal relationships that could have appeared to influence the work reported in this paper.

\section{References:}

1. Honig V, Procházka $\mathrm{P}$, Obergruber $\mathrm{M}$, Roubík H. Nutrient Effect on the Taste of Mineral Waters: Evidence from Europe. Foods. 2020;9(12):1875.

2. Hussain S, Habib-Ur-Rehman M, Khanam T, Sheer A, Kebin Z, Jianjun Y. Health risk assessment of different heavy metals dissolved in drinking water. Int J Environ Res Public Health. 2019;16(10).

3. Wutich A, Rosinger AY, Stoler J, Jepson W, Brewis A. Measuring Human Water Needs. Am J Hum Biol. 2020;32(1):1-17.

4. Armstrong LE, Johnson EC. Water intake, water balance, and the elusive daily water requirement. Nutrients. 2018;10(12):1-25.

5. Şener Ş, Şener E, Davraz A. Assessment of groundwater quality and health risk in drinking water basin using GIS. J Water Health. 2017;15(1):112-32.

6. Benson R, Conerly OD, Sander W, Batt AL, Boone JS, Furlong ET, et al. EPA Public Access. 2018;8:303-12.

7. Wang A, McMahan L, Rutstein S, Stauber C, Reyes J, Sobsey MD. Household microbial water quality testing in a peruvian demographic and health survey: Evaluation of the compartment bag test for Escherichia coli. Am J Trop Med Hyg. 2017;96(4):970-5.

8. Stillo F, Gibson JM. Exposure to contaminated drinking water and health disparities in North Carolina. Am J Public Health. 2017;107(1):180-5.

9. Al Nahian M, Ahmed A, Lázár AN, Hutton CW, Salehin M, Streatfield PK. Drinking water salinity associated health crisis in coastal Bangladesh. Elementa. 2018;6.

10. Vannucci L, Fossi C, Quattrini S, Guasti L, Pampaloni B, Gronchi G, et al. Calcium Intake in bone health: A focus on calcium-rich mineral waters. Nutrients. 2018;10(12):1-12.

11. Wujie, Zhufei, Xujing. The influence of water quality on food quality and the treatment of water for food processing. Procedia Environ Sci [Internet]. 2011;10(PART C):2671-6. Available http://dx.doi.org/10.1016/j.proenv.2011.09.415

12. Shammi M, Rahman M, Bondad S, Bodrud-Doza M. Impacts of Salinity Intrusion in Community Health: A Review of Experiences on Drinking Water Sodium from Coastal Areas of Bangladesh. Healthcare. 2019;7(1):50.

13. Jéquier E, Constant F. Water as an essential nutrient: The physiological basis of hydration. Eur $\mathrm{J}$ Clin Nutr. 2010;64(2):115-23.

14. Underwood MA, Gilbert WM, Sherman MP. Amniotic fluid: Not just fetal urine anymore. J Perinatol. 2005;25(5):341-8.

15. Huang M, Quddus A, Stinson L, Shikany JM, Howard B V., Kutob RM, et al. Artificially sweetened beverages, sugar-sweetened beverages, plain water, and incident diabetes mellitus in postmenopausal women: The prospective Women's Health Initiative observational study. Am J Clin Nutr. 2017;106(2):614-22.

16. Popkin BM, D'Anci KE, Rosenberg IH. Water, hydration, and health. Nutr Rev. 2010;68(8):439-58.

17. Quinete N, Hauser-Davis RA. Drinking water pollutants may affect the immune system: concerns regarding COVID-19 health effects. Environ Sci Pollut Res. 2021;28(1):1235-46. 
18. Ridoutt BG, Baird D, Anastasiou K, Hendrie GA. Diet quality and water scarcity: Evidence from a large Australian population health survey. Nutrients. 2019;11(8):1-15.

19. Genthe B, Kapwata T, Le Roux W, Chamier J, Wright CY. The reach of human health risks associated with metals/metalloids in water and vegetables along a contaminated river catchment: South Africa and Mozambique. Chemosphere. 2018;199:1-9.

20. Geere JAL, Cortobius M, Geere JH, Hammer CC, Hunter PR. Is water carriage associated with the water carrier's health? A systematic review of quantitative and qualitative evidence. BMJ Glob Heal. 2018;3(3):1-24.

21. Setty KE, Kayser GL, Bowling M, Enault J, Loret JF, Serra $\mathrm{CP}$, et al. Water quality, compliance, and health outcomes among utilities implementing Water Safety Plans in France and Spain. Int J Hyg Environ Health. 2017;220(3):513-30.

22. Van Zijl MC, Aneck-Hahn NH, Swart P, Hayward S, Genthe B, De Jager C. Estrogenic activity, chemical levels and health risk assessment of municipal distribution point water from Pretoria and Cape Town, South Africa. Chemosphere. 2017;186:305-13.

23. Wee SY, Aris AZ. Endocrine disrupting compounds in drinking water supply system and human health risk implication. Environ Int [Internet]. 2017;106(January):20733. Available

from: http://dx.doi.org/10.1016/j.envint.2017.05.004

24. Parvizishad M, Dalvand A, Mahvi AH, Goodarzi F. A Review of Adverse Effects and Benefits of Nitrate and Nitrite in Drinking Water and Food on Human Health. Heal Scope. 2017; In Press(In Press).

25. Ward MH, Jones RR, Brender JD, de Kok TM, Weyer PJ, Nolan BT, et al. Drinking water nitrate and human health: An updated review. Int $\mathrm{J}$ Environ Res Public Health. 2018;15(7):1-31.

26. Radfard M, Rahmatinia M, Tabatabaee H, Solimani H, Mahvi AH, Azhdarpoor A. Data on health risk assessment to the nitrate in drinking water of rural areas in the Khash city, Iran. Data Br [Internet]. 2018;21:1918-23. Available from: https://doi.org/10.1016/j.dib.2018.11.007

27. Osunla CA, Okoh AI. Vibrio pathogens: A public health concern in rural water resources in sub-Saharan Africa. Int J Environ Res Public Health. 2017;14(10):1-27.

28. Miller-Robbie L, Ramaswami A, Amerasinghe P. Wastewater treatment and reuse in urban agriculture: Exploring the food, energy, water, and health nexus in Hyderabad, India. Environ Res Lett. 2017;12(7).

29. Li F, Qiu Z, Zhang J, Liu C, Cai Y, Xiao M. Spatial Distribution and Fuzzy Health Risk Assessment of Trace Elements in Surface Water from Honghu Lake. Int J Environ Res Public Health. 2017;14(9):1011.

30. Lapworth DJ, Nkhuwa DCW, Okotto-Okotto J, Pedley S, 43. Stuart ME, Tijani MN, et al. Qualité des eaux souterraines urbaines en Afrique sub-saharienne: état actuel et implications pour la sécurité de l'approvisionnement en eau et la santé publique. Hydrogeol J. 2017;25(4):1093-116.

31. Guo A, Bowling JM, Bartram J, Kayser G. Water, 44 sanitation, and hygiene in rural health-care facilities: a cross-sectional study in Ethiopia, Kenya, Mozambique, Rwanda, Uganda, and Zambia. Am J Trop Med Hyg. 2017;97(4):1033-42.
32. Duijster D, Monse B, Dimaisip-Nabuab J, Djuharnoko P, Heinrich-Weltzien R, Hobdell M, et al. 'Fit for school' - a school-based water, sanitation and hygiene programme to improve child health: Results from a longitudinal study in Cambodia, Indonesia and Lao PDR. BMC Public Health. 2017;17(1):1-15.

33. Prüss-Ustün A, Wolf J, Bartram J, Clasen T, Cumming O, Freeman $\mathrm{MC}$, et al. Burden of disease from inadequate water, sanitation and hygiene for selected adverse health outcomes: An updated analysis with a focus on low- and middle-income countries. Int $\mathrm{J}$ Hyg Environ Health [Internet]. 2019;222(5):765-77. Available from: https://doi.org/10.1016/j.ijheh.2019.05.004

34. Banning A, Benfer M. Drinking water uranium and potential health effects in the german federal state of Bavaria. Int J Environ Res Public Health. 2017;14(8).

35. Wright CJ, Sargeant JM, Edge VL, Ford JD, Farahbakhsh $\mathrm{K}$, Shiwak I, et al. Water quality and health in northern Canada: stored drinking water and acute gastrointestinal illness in Labrador Inuit. Environ Sci Pollut Res. 2018;25(33):32975-87.

36. Ahn SR, Kim SJ. Assessment of integrated watershed health based on the natural environment, hydrology, water quality, and aquatic ecology. Hydrol Earth Syst Sci. 2017;21(11):5583-602.

37. Vaeztavakoli A, Lak A, Yigitcanlar T. Blue and green spaces as therapeutic landscapes: Health effects of urban water canal areas of Isfahan. Sustain. 2018;10(11).

38. Nelson KL, Boehm AB, Davies-Colley RJ, Dodd MC, Kohn T, Linden KG, et al. Sunlight-mediated inactivation of health-relevant microorganisms in water: a review of mechanisms and modeling approaches. Environ Sci Process Impacts. 2018;20(8):1089-122.

39. Ma XY, Li Q, Wang XC, Wang Y, Wang D, Ngo HH. Micropollutants removal and health risk reduction in a water reclamation and ecological reuse system. Water Res [Internet]. 2018;138:272-81. Available from: https://doi.org/10.1016/j.watres.2018.03.059

40. Li XF, Mitch WA. Drinking Water Disinfection Byproducts (DBPs) and Human Health Effects: Multidisciplinary Challenges and Opportunities. Environ Sci Technol. 2018;52(4):1681-9.

41. Ghaderpoori M, Najafpoor AA, Ghaderpoury A, Shams M. Data on fluoride concentration and health risk assessment of drinking water in Khorasan Razavi province, Iran. Data $\mathrm{Br}$ [Internet]. 2018;18:1596-601. Available from: https://doi.org/10.1016/j.dib.2018.04.045

42. Ekenga CC, McElwain CA, Sprague N. Examining public perceptions about lead in school drinking water: A mixedmethods analysis of twitter response to an environmental health hazard. Int J Environ Res Public Health. 2018;15(1).

Ruckart PZ, Ettinger AS, Hanna-Attisha M, Jones N, Davis SI, Breysse PN. The Flint Water Crisis: A Coordinated Public Health Emergency Response and Recovery Initiative. J Public Heal Manag Pract. 2019;25(January 2016):S84-90.

4. O'Brien E, Xagoraraki I. A water-focused one-health approach for early detection and prevention of viral outbreaks. One Heal [Internet]. 2019;7(April):100094. Available

https://doi.org/10.1016/j.onehlt.2019.100094 from: 
45. Carducci A, Federigi I, Dasheng L, Julian R T, Marco V. Making waves: Coronavirus detection, presence and persistence in the water environment: State of the art and knowledge needs for public health. Water Res [Internet]. 2020;179:115907. Available

https://doi.org/10.1016/j.watres.2020.115907

from:

46. Mgbenu CN, Egbueri JC. The hydrogeochemical signatures, quality indices and health risk assessment of water resources in Umunya district, southeast Nigeria. Appl Water Sci [Internet]. 2019;9(1):1-19. Available from: https://doi.org/10.1007/s13201-019-0900-5

47. Kothari MT, Coile A, Huestis A, Pullum T, Garrett D, Engmann C. Exploring associations between water, sanitation, and anemia through 47 nationally representative demographic and health surveys. Ann N Y Acad Sci. 2019;1450(1):249-67.

48. Jia H, Qian H, Qu W, Zheng L, Feng W, Ren W. Fluoride occurrence and human health risk in drinkingwaterwells from southern edge of Chinese loess plateau. Int J Environ Res Public Health. 2019;16(10).

49. Headey D, Palloni G. Water, Sanitation, and Child Health: Evidence From Subnational Panel Data in 59 Countries. Demography. 2019;56(2):729-52.

50. Hasan MK, Shahriar A, Jim KU. Water pollution in Bangladesh and its impact on public health. Heliyon [Internet]. 2019;5(8):e02145. Available from: https://doi.org/10.1016/j.heliyon.2019.e02145

51. George CM, Zohura F, Teman A, Thomas E, Hasan T, Rana S, et al. Formative research for the design of a scalable mobile health program water, sanitation, and hygiene: $\mathrm{CHoBI} 7$ mobile health program. BMC Public Health. 2019;19(1):1-18.

52. Cissé G. Food-borne and water-borne diseases under climate change in low- and middle-income countries: Further efforts needed for reducing environmental health exposure risks. Acta Trop. 2019;194(January):181-8.

53. Boelee E, Geerling G, van der Zaan B, Blauw A, Vethaak AD. Water and health: From environmental pressures to integrated responses. Acta Trop [Internet]. 2019;193(February 2018):217-26. Available from: https://doi.org/10.1016/j.actatropica.2019.03.011

54. Alidadi H, Belin S, Sany T, Zarif B, Oftadeh G, Mohamad $T$. Health risk assessments of arsenic and toxic heavy metal exposure in drinking water in northeast Iran. Environ Health Prev Med. 2019;24(59):1-17.

55. Tumolo M, Ancona V, De Paola D, Losacco D, Campanale $\mathrm{C}$, Massarelli $\mathrm{C}$, et al. Chromium pollution in European water, sources, health risk, and remediation strategies: An overview. Int J Environ Res Public Health. 2020;17(15):125.

56. Schuster RC, Butler MS, Wutich A, Miller JD, Young SL. "If there is no water, we cannot feed our children": The farreaching consequences of water insecurity on infant feeding practices and infant health across 16 low- and middleincome countries. Am J Hum Biol. 2020;32(1):1-38.

57. Saha N, Rahman MS, Ahmed MB, Zhou JL, Ngo HH, Guo W. Industrial metal pollution in water and probabilistic assessment of human health risk. J Environ Manage. 2017; 185:70-8.

58. Rosen MB, Pokhrel LR, Weir MH, Annex R, Engineering G, Ohio T. Supplies in the United States. 2020;843-52.
59. Obasi PN, Akudinobi BB. Potential health risk and levels of heavy metals in water resources of lead-zinc mining communities of Abakaliki, southeast Nigeria. Appl Water Sci [Internet]. 2020;10(7):1-23. Available from: https://doi.org/10.1007/s13201-020-01233-z

60. Moldovan A, Hoaghia MA, Kovacs E, Mirea IC, Kenesz M, Arghir RA, et al. Quality and health risk assessment associated with water consumption - a case study on karstic springs. Water (Switzerland). 2020;12(12).

61. Egbueri JC, Mgbenu CN. Chemometric analysis for pollution source identification and human health risk assessment of water resources in Ojoto Province, southeast Nigeria. Appl Water Sci [Internet]. 2020;10(4):1-18. Available from: https://doi.org/10.1007/s13201-020-011809

62. de Santiago-Martín A, Meffe R, Teijón G, Martínez Hernández V, López-Heras I, Alonso Alonso C, et al. Pharmaceuticals and trace metals in the surface water used for crop irrigation: Risk to health or natural attenuation? Sci Total Environ. 2020;705.

63. Cannas D, Loi E, Serra M, Firinu D, Valera P, Zavattari P. Relevance of essential trace elements in nutrition and drinking water for human health and autoimmune disease risk. Nutrients. 2020;12(7):1-22.

64. Amarasiri M, Sano D, Suzuki S. Understanding human health risks caused by antibiotic resistant bacteria (ARB) and antibiotic resistance genes (ARG) in water environments: Current knowledge and questions to be answered. Crit Rev Environ Sci Technol [Internet]. 2020;50(19):2016-59. Available from: https://doi.org/10.1080/10643389.2019.1692611

65. Ma Z, Jia C, Guo J, Gu H, Miao Y. Features analysis of five-element theory and its basal effects on construction of visceral manifestation theory. J Tradit Chinese Med [Internet]. 2014;34(1):115-21. Available from: http://dx.doi.org/10.1016/S0254-6272(14)60064-9

66. Chung S, Cha S, Lee S-Y, Park J-H, Lee S. The five elements of the cell. Integr Med Res [Internet]. 2017;6(4):452-6. Available from: http://dx.doi.org/10.1016/j.imr.2017.10.002

67. Pitkänen M. The experiments of Masaru Emoto with emotional imprinting of water. 2019;(September 2019):110. Available from: http://tgdtheory.com/.

68. An J, Lee I, Yi Y. The thermal effects of water immersion on health outcomes: An integrative review. Int J Environ Res Public Health. 2019;16(7).

69. Carbajo JM, Maraver F. Sulphurous mineral waters: New applications for health. Evidence-based Complement Altern Med. 2017;2017.

70. Mader S, Brimberg L. Aquaporin-4 Water Channel in the Brain and Its Implication for Health and Disease. Cells. 2019;8(2):90. 